\title{
IRMANDADE DOS COSSACOS DE PRUDENTÓPOLIS: UMA PROPOSTA DE PARTICIPAÇÃO COMUNITÁRIA
}

\author{
L. F. M. SILVA", ${ }^{*}$, J. S. RODRIGUES ${ }^{2}$ e J. S. ANGNES ${ }^{3}$ \\ 1,2,3 Universidade Estadual do Centro-Oeste \\ luciane1712@ hotmail.com*
}

Submetido 29/11/2016 - Aceito 12/07/2018

DOI: $10.15628 /$ holos.2018.5412

\section{RESUMO}

Este artigo aborda a participação comunitária à margem teórica da Psicologia Social Comunitária, destacando a Irmandade Cossacos de Prudentópolis, no estado do Paraná. A partir do estudo da origem, da constituição e da participação comunitária destacamos a trajetória da Irmandade. O intuito de estudá-la surgiu pelas peculiaridades dessa organização, as quais diferem das organizações empresariais. O objetivo geral deste estudo foi compreender a história da Irmandade a partir da perspectiva dos membros do grupo e refletir sobre a participação comunitária na manutenção da tradição ucraniana. A Irmandade apresenta-se uma vez ao ano, na Páscoa, é composta por integrantes do sexo masculino e surgiu informalmente como forma de integração das pessoas na comunidade, após as cerimônias religiosas na Igreja São Josafat de Prudentópolis. Para esta investigação de abordagem qualitativa, utilizamos entrevistas semiestruturadas, pesquisa documental, observação e diário de campo. A partir dos trechos retirados das entrevistas, realizamos as análises e percebemos a constituição da Irmandade, tendo como base os conceitos trazidos pela Psicologia Social Comunitária da América Latina. Os resultados apontaram a Irmandade como uma organização harmônica, consolidada na participação comunitária, nas relações estabelecidas e no sentimento de comunidade. É regulamentada, organizada, depende da participação coletiva e, por esses motivos, é constituída independente de seus territórios.

\section{BROTHERHOOD OF COSSACK PRUDENTÓPOLIS: A PROPOSAL FOR COMMUNITY PARTICIPATION}

\section{ABSTRACT}

This article discusses the community participation in the theoretical scope of Community Social Psychology, highlighting the Brotherhood of Cossack Prudentópolis, in the state of Paraná. From the study of the origin, the constitution and the community participation we highlight the trajectory of the Brotherhood. The purpose of studying it arose because of the peculiarities of this organization, which differ from business organizations. The general objective of this study was to understand the history of the Brotherhood from the perspective of the members of the group and reflect on community participation in upholding the Ukrainian tradition. The Brotherhood presents once a year, in Easter, it is composed of male members and emerged informally as
\end{abstract}

a way of integrating people in the community, after the religious ceremonies in the Church of Saint Josaphat of Prudentópolis. For this qualitative research, we used semi-structured interviews, documentary research, observation and field diary. From the excerpts from the interviews, we performed the analyzes and realized the formation of the Brotherhood, based on the concepts brought by Community Social Psychology in Latin America. The results pointed to the Brotherhood as a harmonic organization, consolidated in community participation, established relationships and community feeling. It is regulated, organized, depends on collective participation and, for these reasons, is constituted independent of its territories.

KEYWORDS: Community Social Psychology in Latin America; Community Participation; Brotherhood of Cossack. 


\section{INTRODUÇÃO}

Este artigo aborda a participação comunitária à margem teórica da Psicologia Social Comunitária, destacando a Irmandade Cossacos de Prudentópolis, no estado do Paraná. A partir do estudo da origem, da constituição e da participação comunitária destacamos a trajetória dessa organização.

Ao conceituarmos organização, devemos entender que tal conceito não deve se limitar à teorias e métodos coloniais presentes na modernidade, no qual ao falarmos em organização remetemos às empresas (Ibarra Colado, 2011). Pelo contrário, essa concepção trata de grupos de indivíduos que interagem independentes de estruturas e hierarquias.

Quando falamos de organização, evidenciamos vínculos e convivências que vão além das estruturas e espaços ocupados, pois trata-se também da motivação que faz com que os indivíduos participem de determinado grupo. Por isso, nosso interesse em pesquisar a Irmandade Cossacos, a qual se destaca pelo sentimento de participação de seus integrantes e pela manutenção da tradição ucraniana.

O grupo em pesquisa foi selecionado por sua peculiaridade em apresentar-se uma vez ao ano, na Páscoa. Inicia-se na Sexta-Feira Santa com a adoração ao Santo Sudário, onde os fiéis vão até a igreja São Josafat, em Prudentópolis, fazem orações e seguem até o Santo Sudário. Os Cossacos são responsáveis por vigiar o sepulcro onde foi colocado o corpo de Jesus Cristo após a crucificação e sua morte.

De acordo com os documentos disponibilizados pela Irmandade dos Cossacos, a origem do nome vem do turco Kozak que significa aventureiros. Os Cossacos são um povo nativo das estepes das regiões do sudeste da Europa, principalmente da Ucrânia e, também, do sul da Rússia. Este povo destaca-se por sua coragem, bravura, força e capacidade militar. Originalmente os Cossacos são compostos por camponeses fugitivos, que escapavam dos senhores das guerras dos feudos polacos e moscovitas. A Irmandade de Cossacos de Prudentópolis é composta por fiéis seguidores aos costumes e tradição do povo ucraniano.

Todo integrante que ingressou na Irmandade tem como juramento de lealdade em primeiro lugar a obrigação de estar em Prudentópolis na Sexta-Feira Santa e no sábado para participar da vigília do Santo Sudário.

Nesse contexto, juntamente com a nova concepção de organização, temos a seguinte indagação: " - Como a Irmandade Cossacos de Prudentópolis consegue manter a participação comunitária dos membros do grupo por meio da tradição passada por gerações se apresentando apenas uma vez no ano? Quais práticas comunitárias são adotadas?

Tal questionamento remete ao propósito da pesquisa entendendo esta como forma de conhecer a vivência do grupo, suas principais características e as formas de compartilhar a tradição ucraniana. Dessa forma, o objetivo geral foi compreender o processo de participação comunitária na Irmandade dos Cossacos do Município de Prudentópolis, no estado do Paraná. A partir disso, pretendíamos entender a história da Irmandade, a partir da perspectiva dos membros 
do grupo e refletir sobre as estratégias utilizadas pelos mesmos para incentivar a participação comunitária na manutenção da tradição ucraniana.

Nesse sentido, verificamos a constituição da Irmandade, tendo como base os conceitos trazidos pela Psicologia Social Comunitária da América Latina (Ansara \& Dantas, 2010). Nesta perspectiva, vimos que esse grupo foi concebido pelo sentimento de comunidade (Elvas \& Moniz, 2010, Sarason, 1974) e depois, organizado formalmente. Isto reflete na essência e manutenção da tradição ucraniana, que consiste na participação comunitária baseada em valores como amizade, espírito de equipe e religiosidade.

Segundo os dados coletados, percebemos que pertencer ao grupo é muito significativo para seus componentes e, por isso, primordiais para que o grupo permanecesse até os dias atuais. Ainda, atribuímos a prática passada por gerações e a religiosidade como motivos de envolvimento e comprometimento dos participantes. Com isso, a história da Irmandade, através da tradição ucraniana, é vista em suas peculiaridades e remetem aos conceitos de participação e sentimento de comunidade, presentes na teoria da Psicologia Social Comunitária Latino-Americana.

\section{PARTICIPAÇÃO COMUNITÁRIA: ENFOQUE DA PSICOLOGIA SOCIAL COMUNITÁRIA DA AMÉRICA LATINA}

Para compreender o conceito de participação comunitária, é necessário perceber a participação sobre diferentes aspectos e, principalmente, analisar as práticas acerca dessa concepção. A participação, de acordo com Nepomuceno, Brito e Góis (2009, p. 76) "é um processo de aprofundamento da inserção social e transformação da realidade, onde o sujeito deixa sua marca na história e é por esta marcado".

Neste sentido, buscamos contextualizar a participação com o conceito de educação libertadora, defendida por Freire (1979). Com essa educação, que vai além da alfabetização, o indivíduo constrói seus próprios conceitos a partir de suas percepções e passa de sujeito alienado a um construtor de sua própria realidade, baseada na imersão do seu cotidiano (Oliveira, Ximenes, Coelho \& Silva, 2008). Tal abordagem nos remete ao entendimento que a participação auxilia o indivíduo a construir sua própria realidade ao mesmo tempo vivencia e torna-se comprometido com suas atividades. Então, passa a compartilhar de seu cotidiano com outros sujeitos, formando uma comunidade.

Conforme descreve Gomes (1999, p. 73),

O termo Comunidade, utilizado hoje em dia na Psicologia Social, é bastante elástico e capaz de incluir em seu escopo desde um pequeno grupo social, um bairro, uma vila, uma escola, um hospital, um sindicato, uma associação de moradores, uma organização não - governamental, até abarcar os indivíduos que interagem numa cidade inteira. $E$ as definições de comunidade tem sido cada vez mais abrangente pois se destinam a cobrir toda esta gama de habitats sociais. 
Com base em Ximenes e Moura Junior (2013, p. 458), "O conceito de comunidade agrupa as pessoas pelo seu local de moradia, em que estão associados valores, crenças e sentimentos entre seus moradores".

De acordo com Bauman (2003, p. 8),

Numa comunidade, todos nós entendemos bem, podemos confiar no que ouvimos, estamos seguros a maior parte do tempo e raramente ficamos desconcertados ou somos surpreendidos. Nunca somos estranhos entre nós. Podemos discutir - mas são discussões amigáveis, pois todos estamos tentando tornar nosso estar juntos ainda melhor e mais agradável do que até aqui e, embora levados pela mesma vontade de melhorar nossa vida em comum, podemos discordar sobre como fazê-lo. Mas nunca desejamos má sorte uns aos outros, e podemos estar certos de que os outros à nossa volta nos querem bem.

Assim, compreendemos que as atividades comunitárias integram as pessoas e podem determinar a participação e o comprometimento de todos em prol de um mesmo objetivo. Além disso, o conceito de comunidade vai além do território e implica as relações estabelecidas pelos seus membros.

Ao participar de uma comunidade, o sujeito fica envolvido com as atividades e desenvolve um sentimento de comunidade. Isso significa que há uma mobilização em favor de todos e independe das vontades individuais. Tal mobilização é compreendida como participação comunitária (Elvas \& Moniz, 2010).

Conforme Nepomuceno, Brito e Góis (2009, p. 77) “A participação comunitária se dá com o aprofundamento da consciência, a prática cooperativa e o exercício do diálogo sobre as questões comunitárias referentes à vida da comunidade".

O conceito de participação comunitária está intimamente ligado ao campo da Psicologia Comunitária e esta, por sua vez, "situa-se dentro de um movimento de transformação histórica da Psicologia Social na América Latina, que afirma a necessidade de um compromisso social com as maiorias populares" (Nepomuceno et al., 2009, p. 76). Assim, na Psicologia Comunitária, a participação deixa de ser um interesse individual para ser coletivo. É um processo relativo às atividades comunitárias e que deve levar em consideração a comunicação e o discernimento por parte dos seus participantes (Nepomuceno et al., 2009).

Tomando o exposto, a Psicologia Social Comunitária no Brasil iniciou em meados da década de $50 \mathrm{com}$ as atividades comunitárias, sendo algo diferenciador das técnicas intervencionistas aplicadas na comunidade, na época. Surge como uma vertente da Psicologia Social da América Latina, em contraposição à Psicologia Americana. Dessa forma, consolidou-se ao longo dos anos por sua visão da realidade e amplitude com outras teorias e áreas de conhecimento (Freitas, 1996).

A atuação em Psicologia Comunitária deu-se no contexto vivenciado pelos países latinoamericanos, incluindo o Brasil, nos quais são altos os índices de pobreza e, consequentemente, 
tornam-se oprimidos e marginalizados. Com isso, a Psicologia Social Comunitária atua como uma Psicologia Social Libertadora, de forma que a consciência e a participação comunitária, além dos processos grupais, intensificam-se pela cooperação e diálogo entre os participantes da comunidade (Freire, 1979; Moura Junior et al., 2013).

Nesse contexto, percebemos que é importante compreendermos que o modo de participação relaciona à conscientização que o sujeito tem sobre si mesmo e a comunidade e, principalmente, a maneira como interage com os outros indivíduos, o que traz a ele o sentimento de pertencer a uma comunidade e, consequentemente, a satisfação e o bem-estar das relações estabelecidas (Freire, 1979; Elvas \& Moniz, 2010).

Além disso, a participação comunitária é um modo de participação social. A atividade comunitária constitui os esforços da participação social com base no envolvimento dos indivíduos e de acordo com os objetivos determinados. Conforme Nepomuceno et al. (2013, p. 48) "É um processo dialético de imbricação do sujeito com a realidade em que, por meio da atividade, o indivíduo transforma o mundo e a si mesmo, onde objetivo e subjetivo encontram-se atrelados de modo indissociável".

O envolvimento comunitário foi embrionário para que a participação comunitária surgisse. Com isso, a mobilização e o envolvimento da comunidade contribuem para o sentimento de comunidade, que pode ser entendido como o sentimento de pertencer a uma rede de relacionamentos em que os indivíduos compartilham e são dependentes (Sarason, 1974).

A respeito do sentimento de comunidade, Elvas e Moniz (2010, p. 452 apud Mcmillan \& Chavis, 1986, p. 9) afirmam:

Para McMillan e Chavis, o sentimento de comunidade baseia-se em quatro elementos essenciais que definem as qualidades específicas do conceito. Estes elementos são: fazer parte de; influência; integração e satisfação das necessidades e partilha de ligações emocionais, que são definidos como sendo "o sentimento que os membros têm de pertença, o sentimento que os membros importam para um outro membro e para o grupo, e a conviç̧ão de que as necessidades dos membros serão alcançadas através de um compromisso de união".

A partir de tal citação, compreendemos que o sentimento de comunidade corrobora para que, ao mesmo tempo, o sujeito participe e compartilhe, de forma subjetiva, suas vivências e percepções. Assim, a participação comunitária torna-o consciente de sua capacidade de organizarse e mudar sua própria realidade.

\section{ORIENTAÇÕES METODOLÓGICAS: OS CAMINHOS TRILHADOS PARA A INVESTIGAÇÃO DA HISTÓRIA DA IRMANDADE DOS COSSACOS DE PRUDENTÓPOLIS}

Para este estudo, utilizamos as entrevistas semiestruturadas como forma de entendermos a história da Irmandade Cossacos de Prudentópolis e identificarmos como a Irmandade mantém 
suas tradições até os dias atuais. Tendo esse objetivo, elegemos a pesquisa qualitativa por considerarmos "a pesquisa qualitativa tem o ambiente natural como fonte direta de dados e o pesquisador como instrumento fundamental". (Godoy, 1995, p. 62).

A percepção teórica que embasou a pesquisa deu-se a partir da Psicologia Social Comunitária da América Latina e corroborou para que déssemos parâmetros para o entendimento da participação comunitária e seus reflexos na Irmandade Cossacos.

A ideia de pesquisarmos a Irmandade surgiu pelo fato dos Cossacos apresentarem-se uma única vez ao ano, no período da Páscoa e manterem as tradições ucranianas com bases históricas e religiosas, além de outras peculiaridades. Por ser uma organização, diferente das demais pesquisadas, chamou-nos atenção em descobrir como se organizam e conseguem manter-se por tantos anos.

Uma das pesquisadoras já havia assistido às apresentações e fez o primeiro contato com a Irmandade, a fim de coletar documentos e fazer o convite para participar de nossa pesquisa. A resposta foi positiva e começamos os primeiros passos da investigação.

Buscamos por documentos produzidos sobre a Irmandade e apenas encontramos alguns folders fornecidos pelos mesmos durante o primeiro contato com a organização. Para Flick (2004), a pesquisa documental é utilizada como uma estratégia complementar para outras técnicas, como a entrevista. Dessa forma, encontramos uma página eletrônica de uma rede social utilizada pelo grupo para divulgar fotos das apresentações. Dessa forma, decidimos investigar e escrever sobre os Cossacos como forma de contribuir para a história e para o conhecimento de uma nova forma de organização, diferente dos parâmetros conhecidos.

Optamos pelas entrevistas semiestruturadas na "expectativa de que é mais provável que os pontos de vista dos sujeitos entrevistados sejam expressos em uma situação de entrevista com um planejamento relativamente aberto do que em uma entrevista padronizada ou em um questionário" (Flick, 2004, p. 89).

Para isso, entrevistamos três participantes, escolhidos pelas fases principais do grupo: o idealizador, o capitão e um membro da Irmandade. As entrevistas foram individuais, gravadas, ocorreram no mês de julho de 2016 e tiveram duração média de trinta minutos. A observação foi primordial para que construíssemos a análise dos dados, além do diário de campo que utilizamos para anotar as percepções durante a coleta de dados e, posteriormente, auxiliaram nas análises realizadas.

O instrumento da coleta de dados utilizado foi o roteiro de entrevista que contou com onze questões relacionadas às interfaces: origem (duas questões); organização (duas questões); participação (três questões); relação (três questões); e significado (uma questão). Também utilizamos o Termo de Consentimento Livre e Esclarecido (TCLE), o qual esclareceu as propostas da pesquisa, as questões éticas e serviu de convite para os participantes desse estudo. Vale mencionar que tivemos autorização dos entrevistados para mencionarem seus nomes na pesquisa. 
Durante as entrevistas identificamos um clima favorável e informal, o que contribuiu para o distanciamento entre pesquisador e pesquisado, além de conversas que permitiram a "expressão livre dos interlocutores" (Godoi \& Mattos, 2010, p. 318). Verificamos, também, que após cessar a gravação, os entrevistados nos deram mais detalhes sobre suas percepções a respeito da Irmandade e suas experiências. Isso enriqueceu a pesquisa e mostrou que o diálogo informal trouxe mais subsídios à coleta de dados.

Após a transcrição das entrevistas, realizamos a análise dos dados com base nas interfaces, conforme apresentadas no Quadro 1.

Quadro 1: Interfaces orientadoras da análise dos dados

\begin{tabular}{|c|c|}
\hline Interfaces & Expressões utilizadas \\
\hline Origem & $\begin{array}{l}\text { "A Irmandade surgiu como forma das pessoas se reunirem depois das } \\
\text { celebrações na igreja" (Capitão Emerson, 2016). } \\
\text { "(...) foi uma iniciativa espontânea dos jovens que faziam parte da } \\
\text { Congregação Mariana e dos jovens do grupo Vesselka (...)" (Soldado } \\
\text { Rodrigo, 2016). }\end{array}$ \\
\hline Organização & $\begin{array}{l}\text { "O grupo é formado por um presidente, o capitão maior que a gente } \\
\text { chama (...) os onze capitães respondem por todo o grupo(...)" (Presidente } \\
\text { Marcos, 2016). } \\
\text { “(...)a gente tem } 11 \text { capitães e tudo é decidido junto" (Capitão Emerson, } \\
\text { 2016). }\end{array}$ \\
\hline Participação & $\begin{array}{l}\text { "Porque desde pequeno eu via os guardas na Páscoa (...) isso foi virando } \\
\text { admiração e foi virando vontade de participar" (Soldado Rodrigo, 2016). } \\
\text { "(...) eu sempre gostei da cultura ucraniana, sabe, eu sou um apaixonado" } \\
\text { (Presidente Marcos, 2016). }\end{array}$ \\
\hline Relação & $\begin{array}{l}\text { "a gente se comporta como uma irmandade mesmo" } \\
\text { (Soldado Rodrigo, 2016). } \\
\text { “(...)é uma relação harmoniosa, por isso que é uma irmandade, é irmãos, } \\
\text { irmãos” (Presidente Marcos, 2016). }\end{array}$ \\
\hline Significado & $\begin{array}{l}\text { "Significa um momento forte de reflexão, de repensar a vida, repensar os } \\
\text { erros (...)" (Soldado Rodrigo, 2016). } \\
\text { "(...) tenho orgulho de fazer parte dos Cossacos, da tradição ucraniana (...)" } \\
\text { (Capitão Emerson, 2016). }\end{array}$ \\
\hline
\end{tabular}

Com base nas interfaces orientadoras, elaboramos a análise dos dados descrita com base nas categorias das entrevistas e dos métodos e técnicas utilizadas na pesquisa, de acordo com o texto a seguir. Com a autorização dos Entrevistados, durante as análises, utilizamos seus nomes, conforme a hierarquia do grupo: o presidente, Marcos Boiko; o capitão, Emerson Luiz Scharnei e o soldado, Giovane Rodrigo Michalovski. 


\section{A HISTÓRIA CONSTRUÍDA PELA ORIGINALIDADE DOS GUARDIÕES DO SANTO SUDÁRIO: IRMANDADE E RELIGIOSIDADE}

Relatamos aqui a análise dos dados com base nas categorias retirados das entrevistas, que retratam a origem; organização; participação; relação e significados presentes na Irmandade Cossacos de Prudentópolis. Procuramos identificar diferentes nuances a respeito da construção e manutenção desta organização e, principalmente discutir a participação comunitária, estabelecida a partir da Psicologia Social Comunitária da América Latina.

Conforme dados coletados nos discursos e nos documentos disponibilizados, verificamos que a Irmandade dos Cossacos surgiu como uma integração da comunidade que se reunia logo após as cerimônias religiosas na igreja São Josafat, em Prudentópolis. Assim, inspiraram-se na história dos Cossacos, guardiões do Santo Sudário, para criar as apresentações e deram continuidade à vigília na Sexta-feira Santa, que antecede a Páscoa.

Notamos que todos os Entrevistados mencionaram sobre a origem da Irmandade baseada na história dos Cossacos, vindos da Ucrânia. Vale ressaltar que além da tradição mantida, a religiosidade está intimamente ligada ao grupo, desde suas origens com a guarda do Santo Sudário até a constituição da Irmandade Cossacos de Prudentópolis, quando seus fundadores se reuniam no pátio da Igreja São Josafat, após as celebrações, idealizando e consolidando a Irmandade.

A Irmandade surgiu como forma das pessoas se reunirem depois das celebrações na igreja, aí o pessoal se reunia. No começo não tinha uma organização, não era constituída com presidente, tesoureiro...Só depois de 2000 que colocamos tudo no papel, fizemos um estatuto com CNPJ. A história do grupo começou tudo com o Marcos Boiko, foi ele quem começou e tirou tudo do bolso dele, ele pagou todas as roupas do grupo e com o passar do tempo fomos pagando para ele. Ele foi um grande incentivador do grupo (Capitão Emerson, Entrevista 1, 2016).

Em 2008 que nós reformulamos todo o grupo. Então nós extinguimos praticamente tudo para trás. Não deixamos nada. O que acontecia na época, havia muitos problemas porque o que acontecia havia vários grupos dentro da paróquia. Era a congregação mariana, era o grupo Vesselka. Eram paroquianos, era o pessoal do coral. Eram grupos de da paróquia que estavam é que faziam parte daquela época que eram conhecidos os guardas, não tinham nome como hoje que são a irmandade dos Cossacos. Então em 2008 nos reunimos as pessoas que ainda participavam do grupo e reformulamos todo ele. Como é que nós fizemos isso? Extinguimos tudo pra trás, praticamente foi tudo eliminado, não existe mais grupos. Existe um grupo só. E formamos na época a irmandade dos Cossacos. Esse grupo hoje é nós. Em 2016 agora nós estamos praticamente com 150 componentes (...) (Presidente Marco, Entrevista 2, 2016). 
Diante dos discursos e dos registros do diário de campo, verificamos que esta organização, ao contrário das empresariais, iniciou-se informalmente, apenas com o intuito de integrar os participantes da igreja, e depois, em 2008, consolidou-se como Irmandade Cossacos, inclusive com a criação de um estatuto e do Cadastro Nacional de Pessoas Jurídicas (CNPJ).

Concordamos com Ibarra Colado (2011) quando discute o conceito de organização. O autor destaca que esta não pode ser vista apenas pelos conceitos tradicionais, pois vai além das estruturas centralizadas. Isso significa pensar em como as pessoas se organizam e determinam seus objetivos, de acordo com seus espaços e contextos.

Perguntamos aos Entrevistados como é a organização da Irmandade e se existe alguma hierarquia. Segundo o Presidente Marcos,

A partir de 2008 foram ingressando os novos componentes até 2016 nós chegamos a 150 componentes que hoje nós estamos formados. O que que nós fizemos na sequência? Como nós tivemos muitos componentes, nós dividimos esses grupos então a vigília do Santo Sudário se dá, começa na sexta-feira de manhã, inicia e termina no sábado à noite. Então nós pegamos esses componentes os cento e cinquenta componentes e começamos a dividir, nos reunimos todos esses componentes e dividimos eles em vários, vários grupos, cada grupo tem o seu comandante, nós somos em onze comandantes, então eu sou o presidente e tem mais dez comandantes né que, tem os seus grupos, cada grupo tem mais quatorze, quinze, dezesseis componentes, pra fechar os cento e cinquenta componentes. Começamos na sexta-feira de manhã e os grupos vão trocando a cada três, quatro horas, vai se trocando. Assim não há, não há um cansaço físico, né. Todo mundo tem os intervalos para descanso e tudo mais. Porque a gente é ininterrupto, a nossa vigília, né. Começa na sexta-feira e termina no sábado à noite (Entrevista 2, 2016).

Pelo discurso acima, percebemos que há uma forma de organização na Irmandade, estabelecida para dar suporte às atividades dos Cossacos, marcada por liderança, divisão das tarefas e momento de descanso.

Ainda, de acordo com o Capitão Emerson (Entrevista 1, 2016) "O grupo tem um presidente e tem os capitães. Cada capitão cuida dos outros 10 componentes, então hoje a gente tem 11 capitães e tudo é decidido junto". Nesse trecho, reiteramos a organização da Irmandade através da divisão do trabalho, em que todas as decisões são tomadas pelo coletivo.

O que diferencia essa organização das organizações empresariais é que a Irmandade não visa lucros, e sim, possui objetivo de levar sua cultura ucraniana às pessoas. Conforme relata o Presidente Marcos (Entrevista 2, 2016) “Nós não temos necessidade de tá gerando lucro, como numa empresa, mas nós temos, como diz os mesmos fundamentos de gerenciar uma empresa, o nosso grupo também". Isso significa que a organização não cobra nenhum valor do público que assiste às apresentações, apenas estipulou um valor de mensalidade pago por seus integrantes, como forma de contribuir com a manutenção de vestimentas e documentos utilizados. 
Além disso, existem regras para integrar a Irmandade, segundo o Presidente Marcos (Entrevista 2, 2016)

E nós temos dois lemas que é fundamental e nós temos regras também. Não vamos dizer que não temos regras. A primeira regra é que o componente que entrar ele não pode sair, ele é como diz, ele fica lá eternamente. Não eternamente, mas até a o dia que ele não tiver condições de fisicamente e ou, ou estar de corpo presente ali. A segunda regra é sempre estar em Prudentópolis na Semana Santa, para fazer esse ato de fé. Esse ato cultural. São as duas regras básicas. As demais a gente estabelece. São normais, mas são as duas principais.

Por outro lado, assim como em qualquer tipo de organização, também houve dificuldades na trajetória. Duas delas surgiram logo no início, quando os Cossacos ainda eram conhecidos apenas como os guardiões do Santo Sudário.

Acredito que a dificuldade foi logo no começo quando não tinha as vestimentas parao grupo, o Marcos comprou tudo com dinheiro dele, foi tudo com muito esforço. Depois outra dificuldade foi do número de integrantes para faze a vigília, eram poucos e era complicado no começo, hoje tem mais participantes aí fica mais fácil. Acredito que foram essas as maiores dificuldades mesmo (Capitão Emerson, Entrevista 1, 2016).

O Presidente Marcos (Entrevista 2, 2016) detalha em seu discurso:

E a partir de 2008 nós também tínhamos um problema sério que era a questão dos trajes. Nós não tínhamos uma estrutura para atender a toda a demanda que nós tínhamos necessidade. Então o que nós fizemos? Os trajes na época eram emprestados do grupo Vesselka. Como eles tinha, eles têm os seus afazeres, nós priorizamos em construir o nosso traje. Então na época a gente financiou. Para depois a gente consequentemente fazer alguns eventos e cobrar uma anuidade do grupo. De cada componente para pode ressarcir esse investimento que foi inicial. Nós começamos em 2008 praticamente com 40 componentes que eram o que estavam o grupo na época. Os 40 componentes e mandamos já de cara fazer 40 trajes no início, então já foi o investimento inicial sem ter recursos, sem ter nada. Nós já começamos priorizando trajes, já começamos a fazer nossos materiais. Que é o que é nossos utilitários como espadas, lanças, são algumas ferramentas, que nós usávamos na época emprestadas também nós também fizemos. Na sequência a partir de 2008 foram ingressando os novos componentes até 2016 nós chegamos a 150 componentes que hoje nós estamos formados.

Apesar dos desafios com relação a ausência de recursos para comprar os trajes e poucos integrantes para realizar a vigília, a Irmandade foi reestruturada a partir do ano 2008, com a criação de um estatuto e consolidou-se ao longo dos anos com a participação de novos 
integrantes, com a divisão das tarefas e com o apoio da comunidade que assistiam às apresentações dos Cossacos.

Ainda, compreendemos que a dificuldade foi superada pelo trabalho da coletividade, pois o presidente do grupo, em 2008, pagou os custos das vestimentas e, depois, os valores foram devolvidos pelo grupo. Ademais, os acessórios que compunham os trajes foram confeccionados pela própria Irmandade.

Evidenciamos, também, outra característica peculiar dos Cossacos, que constitui na participação comunitária (Nepumoceno et al., 2009). Notamos com os discursos das entrevistas que não há um processo de seleção para participar da Irmandade, os integrantes convidam colegas e, também, recebem aqueles que desejam participar. De acordo com o Soldado Rodrigo (Entrevista 3, 2016) "qualquer jovem a partir dos quinze anos que tem interesse de participar da Irmandade pode tá fazendo parte, não tem nenhum processo de seleção".

Dessa forma, entendemos que a participação na Irmandade é um processo espontâneo acompanhado do envolvimento comunitário e do sentimento de pertencer a um grupo ou comunidade. Ainda notamos que o interesse coletivo transpõe o interesse individual (Elvas \& Moniz, 2010).

Logo no início da primeira Entrevista, observamos que o Capitão Emerson, ao perguntarmos sobre o sigilo ou não de sua identidade na transcrição da pesquisa, respondeu "Olha se os demais que forem Entrevistados aceitar de usar o nome, tudo bem, eu aceito também. Se eles não quiserem, eu também não. Porque falo em nome do grupo, daí depende do grupo". Observamos que esse Entrevistado entende a Irmandade como um interesse coletivo e não individual. É visível o sentimento de comunidade (Sarason, 1974) entre os Cossacos, pois fazem parte de uma rede de relacionamentos, são dependentes, compartilham e são comprometidos (Elvas \& Moniz, 2010; Mcmillan \& Chavis, 1986).

Quando questionamos aos integrantes quais foram os motivos que levaram à participação na Irmandade, o Presidente Marcos (Entrevista 2, 2016), respondeu "Eu sempre gostei da cultura ucraniana, sabe, eu sou um apaixonado, participei do Vesselka, mais ou menos uns quinze anos, hoje eu sou, como diz um apoiador do grupo, eu admiro muito o grupo". Por sua vez, o Soldado Rodrigo (Entrevista 3, 2016) mencionou,

Porque desde pequeno eu via os Guardas na Páscoa e primeiro eu tinha medo e achava que eles tinham uma função de assustar as pessoas, é, mas depois quando eu fui crescendo, isso foi virando, isso foi virando admiração e foi virando vontade de participa então quando eu atingi idade, que a idade mínima é 15 anos, eu quis entra e foi a primeira vez que tirei guarda.

Diante das categorias, observamos a satisfação em participar da Irmandade Cossacos e, principalmente o sentimento de comunidade internalizado através da tradição ucraniana. Isso também corrobora para a originalidade da Irmandade até os dias atuais.

Quanto às relações estabelecidas pelos Cossacos, evidenciamos harmonia, irmandade e comprometimento. Além disso, há problemas e discussões, típicos das relações interpessoais. 
Percebemos que a Psicologia Social Comunitária está aliada à Psicologia Social Libertadora (Freire, 1979; Góis, 2008; Moura Junior et al., 2013) no momento em que há compreensão, diálogo e cooperação entre os integrantes da Irmandade.

O Soldado Rodrigo (Entrevista 3, 2016) afirma “(...) a gente não se reúne muito durante o ano, mas durante o período que nós estamos juntos na Páscoa é um clima muito forte, é a gente se comporta como uma irmandade mesmo, é um clima de companheirismo de amizade, de respeito. Então é muito bacana pode conviver".

É uma relação harmoniosa, por isso que é uma irmandade, é irmãos, irmãos, é como uma família, a gente senta, discute, briga, e como diz, não é só alegria, mas tem os momentos também é, as discussões, os problemas que surgem em qualquer, qualquer outro grupo, acho que é normal, e é normal isso. A gente pode dizer que ninguém é perfeito, mas a gente sempre tá tentando trabalhar em harmonia (Presidente Marcos, Entrevista 2, 2016).

Entendemos os relacionamentos entre os integrantes da Irmandade como fator primordial para criação de uma participação efetiva e libertadora, ao mesmo tempo. Isso significa que esta organização transformou sua realidade e está submersa no cotidiano da comunidade (Freire, 1979; Oliveira et al., 2008). Ainda sobre a participação, esta assume um significado para os participantes da Irmandade.

Significa um momento forte de reflexão, de repensar a vida, repensar os erros, é. Com certeza é um motivo de muita alegria de muita satisfação, é, pode sabe que a gente trabalha pra mante uma cultura que é tão rica, tão, tão vasta, então com certeza, eu tenho muito orgulho de faze o meu papel, mesmo que seja pouco, mas faze o meu papel pra mante essa tradição viva (Soldado Rodrigo, Entrevista 3, 2016).

Bom (pausa mais longa) (sorriso) significa muito pra minha vida, desde quando comecei a participar até hoje tenho orgulho de fazer parte dos Cossacos, da tradição ucraniana. Além de tudo, ali somos amigos, irmãos, somos unidos, fazemos tudo pela fé e isso traz muito aprendizado para vida, eu gosto de trabalhar com pessoas, participo dos Cossacos e, também, dos Vesselkas e gosto muito do que faço. É bom ver que o grupo cresceu e hoje vem gente de vários lugares assistir, é muito gratificante (Capitão Emerson, Entrevista 1, 2016).

Comparando os dois discursos verificamos a essência que a Irmandade traz aos seus participantes e a satisfação e o orgulho que sentem por transmitirem a cultura ucraniana. Além disso, a religiosidade está presente nos discursos como base para as relações estabelecidas. 0 aprendizado também é um fator relevante que corrobora para que os participantes queiram permanecer na Irmandade e que se relacionem como irmãos. 
Quando questionamos os Entrevistados sobre que motivos mantém a Irmandade até os dias atuais, responderam:

Acho que primeiramente é a vontade dos líderes, eu acho que hoje nós temos os líderes que comandam que estão sempre presentes, né, é como se fosse um dono de uma empresa, é ele que a empresa vá para frente ele quer que a empresa produza, que a empresa de lucro, enfim o nosso não é o caso, mas é a liderança, as lideranças que acompanham que puxam os demais, então e também mantendo a cultura e principalmente a fé, eu acho que primordial é a fé. A gente procura estar presente, né, nos eventos e tudo mais. Por causa da nossa fé (Presidente Marcos, Entrevista 2, 2016).

Com certeza o principal motivo é a manutenção a cultura ucraniana e, também, porque é muito gostoso faze parte é os momentos de reflexão que a gente passa lá na frente junto do corpo do Cristo é, é um momento único para reflexão pessoal, pra reflexão interior, então com certeza é por isso que quem tira guarda uma vez nunca mais quer sair (Soldado Rodrigo, Entrevista 3, 2016).

Diante dos discursos vimos que, na opinião dos Entrevistados, a durabilidade e manutenção da organização é a tradição ucraniana, a religiosidade e a forma de liderança. Com as observações, evidenciamos que a fé estava presente não só nos discursos, mas no cuidado e no respeito que se referiam a vigília do Santo Sudário.

Após desligarmos o gravador, notamos que todos os entrevistados falaram com mais detalhes sobre a Irmandade, relatando apresentações e inclusive nos convidando para assisti-las. Com isso, percebemos que os Entrevistados ficaram mais tranquilos conosco depois que o gravador foi desligado e a conversa fluiu com mais naturalidade. Cada vez que descreviam como era montado o cenário, a expectativa dos participantes sobre o evento e a tradição ucraniana, notávamos o quanto era gratificante para eles participarem da Irmandade. Isso demonstra o sentimento de pertencer ao grupo como algo internalizado pelos participantes.

\section{CONSIDERAÇÕES FINAIS}

Entendemos a Irmandade dos Cossacos como uma organização que vai além dos conceitos trazidos pelas organizações empresariais, pois foi formulada apenas como uma forma de integração, união e participação entre seus integrantes, além da preservação da tradição ucraniana com base na religiosidade da comunidade. Porém, possui características de atividades organizacionais, como hierarquia, regras, divisão de tarefas, reuniões, entre outras. Além disso, como toda organização, passa por desafios e é construída com base nas relações estabelecidas. 
Também percebemos que a Irmandade teve dois momentos distintos. O primeiro, na sua origem, quando apenas existiam os Guardiões do Santo Sudário, organizados informalmente e o segundo, a partir de 2008, quando foi constituída a Irmandade dos Cossacos, com a criação do estatuto e da divisão de tarefas.

De acordo com os discursos coletados, a relação entre os membros é familiar e o companheirismo e o respeito imperam sobre qualquer espécie de conflito que possa ocorrer. Constatamos, também o sentimento de responsabilidade e dedicação do presidente do grupo, o qual tomou a iniciativa e se empenhou em transformar o pequeno grupo informal de guardas na Irmandade dos Cossacos. Essa atualmente conta com 150 integrantes e serve de exemplo para outras comunidades.

Destacamos que a participação comunitária atuou como libertadora ao passo que a Irmandade, apesar de ter enfrentado alguns desafios, consolidou-se ao longo dos anos e, consequentemente, o sentimento de pertencer a uma comunidade tornou-se o diferencial para a originalidade dos Cossacos.

A Irmandade não disponibiliza documentos publicitários, apenas possui uma página eletrônica numa rede social para divulgar fotos de suas apresentações. Assim, também tivemos acesso a alguns documentos que a própria organização nos forneceu. Construímos a pesquisa com base nesses documentos, entrevistas e observações realizadas.

Enquanto coletávamos as entrevistas notamos que, em todos os discursos, os participantes tinham orgulho em participar da Irmandade. Isso nos chamou atenção, pois além das palavras, as expressões faciais, os gestos, nos confirmavam as características da participação comunitária que é o envolvimento, a cooperação e o sentimento de pertença.

Além disso, a religiosidade e a tradição ucraniana possuem significância para a participação e comprometimento de seus integrantes. Outro aspecto importante observado é que os participantes entendem a vigília como um processo de reflexão e aprendizado para suas vidas.

Consideramos a Irmandade como uma organização harmônica, consolidada na participação comunitária, nas relações estabelecidas e no sentimento de comunidade. É regulamentada, organizada, depende da participação coletiva e, por esses motivos, é constituída independente de seus territórios.

Este estudo também deixa novas possibilidades de pesquisas com grupos organizados nas comunidades, como por exemplo, associações de moradores, cooperativas e movimentos sociais, entre outros. Além disso, pesquisas dessa natureza auxiliarão estudos na área de Administração, pois o conceito de organização deve ser entendido além dos espaços e das estruturas.

\section{REFERÊNCIAS}

Ansara, S. \& Dantas, B. S. A. (2010). Intervenções psicossociais na comunidade: desafios e práticas. Psicologia \& Sociedade, 22(1), 95-103. Recuperado em 20 junho 2016, de http://www.scielo.br/pdf/psoc/v22n1/v22n1a12.pdf 
Bauman, Z. (2003). Comunidade: a busca por segurança no mundo atual. Rio de Janeiro: Jorge Zahar. Editor.

Elvas, S., Moniz \& M. J. V. (2010). Sentimento de comunidade, qualidade e satisfação de vida. Análise Psicológica. Recuperado em 17 junho 2016, de http://www.scielo.mec.pt/scielo.php?script=sci_arttext\&pid=S0870-82312010000300006

Flick, U. (2004). Entrevistas semiestruturadas. p. 89-108. In FLICK, U. Uma introdução à pesquisa qualitativa. 2. ed. Porto Alegre: Bookman.

Freire, P. (1979). Educação como Prática de Liberdade. 9. ed. Rio de Janeiro: Paz e Terra.

Freitas, M. (1996). Psicologia na comunidade, Psicologia da Comunidade e Psicologia (Social) Comunitária: Práticas da Psicologia em comunidade nas décadas de 60 a 90, no Brasil. In R. Campos (Ed.), Psicologia Social Comunitária: Da solidariedade à autonomia. (pp. 54-80). Petrópolis, RJ: Vozes.

Godoi, C. K. \& Mattos, P. L. C. L. (2010). Entrevista qualitativa: instrumento de pesquisa e evento dialógico. p. 301-320. In GODOI, C. K. Bandeira-de-Mello, R.; Silva, A. B. (org.). 2.ed. Pesquisa qualitativa em estudos organizacionais: paradigmas, estratégias e métodos. São Paulo: Saraiva.

Godoy, A. S. (1995). Introdução à pesquisa qualitativa e suas possibilidades. Revista de Administração de Empresas, São Paulo, v. 35, n. 2, p. 57-63. Recuperado em 15 julho 2016, de http://rae.fgv.br/sites/rae.fgv.br/files/artigos/10.1590_S0034-75901995000200008.pdf

Gomes, A. M. de A. (1999). Psicologia Comunitária: Uma abordagem Conceitual. Revista Psicologia: Teoria e Prática, São Paulo, 1 (2), 71-79. Recuperado em 10 junho 2016, de http://editorarevistas.mackenzie.br/index.php/ptp/article/view/1154

Ibarra-Colado, E. (2006). Organization studies and epistemic coloniality in Latin America: thinking otherness from the margins. Organization, v. 13, n. 4, p. 463-488. Recuperado em 12 maio 2016, de http://org.sagepub.com/content/13/4/463.short

Irmandade dos Cossacos de Prudentópolis, PR (2016). [Folheto]. Prudentópolis. Makograf.

Moura Junior, J. F., Cardoso, A.A.V., Rodrigues, D. C., Vasconcelos, R. M. \& Ximenes, V. M. (2013). Práxis em Psicologia Comunitária: Festa de São João como atividade comunitária. Revista Ciência em Extensão, 9 (1), 104-122. Recuperado em 20 junho 2016, de http://ojs.unesp.br/index.php/revista_proex/article/view/744

Nepomuceno, L. B. Brito, A. V de. \& Góis, C. W. de L. (2009). Dialogando com Lideranças Comunitárias sobre participação: um estudo sócio-psicológico. Sanare (Sobral). v. 8, p. 7485. Recuperado em 10 maio 2016, de https://sanare.emnuvens.com.br/sanare/article/view/46

Nepomuceno, L.B., Ximenes, V. M. \& Moreira, A.E.M.M, Nepomuceno, B.B. (2013). Participação Social em Saúde: Contribuições da Psicologia Comunitária. Psico, Porto Alegre, PUCRS, v. 44, n. 1 p. 45-54, jan./mar. Recuperado em 15 maio 2016, de http://revistaseletronicas.pucrs.br/revistapsico/ojs/index.php/revistapsico/article/view/1010 2

Oliveira, F. P. Ximenes V.M, Coelho, J.P.L \& Silva, K.S. (2008). Psicologia comunitária e educação libertadora. Psicologia: Teoria e Prática, v. 10, n. 2, p. 147-161. Recuperado em 10 junho 2016, de http://pepsic.bvsalud.org/scielo.php?script=sci_arttext\&pid=S1516-36872008000200012

Sarason, S. B. (1974). The psychological sense of community: Prospects for a Community Psychology. San Francisco. Jossey-Bass. 
Ximenes, V. M \& Moura Junior. J. F. (2013). Psicologia Comunitária e comunidades rurais do Ceará: caminhos, práticas e vivências em extensão universitária. In Leite, J. F. \& Dimenstein, M. (Eds). Psicologia e contextos rurais (pp. 453-476). Natal: EDUFRN. 